\title{
Review of D-STATCOM for Stability Analysis
}

\author{
Pradeep Kumar ${ }^{1}$, Niranjan Kumar ${ }^{2}$ \& A.K.Akella ${ }^{3}$ \\ ${ }^{123}$ Deptt. of Electrical Engineering, National Institute of Technology, Jamshedpur \\ Jharkhand (INDIA)
}

\begin{abstract}
A Static Compensator (STATCOM) is a flexible ac transmission system (FACTS) controller, which can either absorb or deliver reactive power to a power system. Distribution STATic COMpensator (DSTATCOM) is proposed for compensation of reactive power and unbalance caused by various loads in distribution system. Distribution static compensator is based on the VSC principle. A D-STATCOM injects a current into the system to correct the voltage sag, swell and power factor. Distribution Static Synchronous Compensator (D-STATCOM) is an effective measure to maintain voltage stability and improve power quality of distribution grid. This paper deals with the modeling and control scheme of D-STATCOM. A stability analysis of D-STATCOM is obtained by bode plot approach. The theoretical analysis and design are verified by the results.
\end{abstract}

Keywords: Distribution System, Power Quality, Custom Power Device, Shunt Compensation Device, Distribution Static Compensator (D-STATCOM).

\section{INTRODUCTION}

The high power quality is requested by manufacturing factories and commercial buildings dealing with information. This circumstance is caused by the fact that poor power quality gives the bad effects to the quality of products and therefore, results in financial losses. According to EPRI report (1995), the revenue losses due to poor power quality to U.S. business alone were $\$ 400$ billion per year . Power quality problems are caused by dynamic or non-linear loads and interaction between the load and network. Outage, voltage sag and swell, voltage flicker, harmonic interference, and unbalance are some of the most common problems encountered.

Today, new technologies known as Custom Power [1], using power electronics-based concepts, have been developed to provide protection from power quality problems. Generally, Custom Power equipments are divided by series-connected compensator like DVR (Dynamic Voltage Restorer), shunt-connected compensator like D-STATCOM (Distribution Static Compensator), and series and shunt compensator like UPQC (Unified Power Quality Compensator).

In many instances, the use of Distribution Static Synchronous Compensator (D-STATCOM) can be some of the most cost-effective solutions for these types of power quality problems.

When a fault happens in a distribution network, sudden voltage sag will appear on adjacent loads. D-STATCOM installed on a sensitive load, restores the line voltage to its nominal value within the response time of a few milliseconds thus avoiding any power disruption to the load. Currently, most of the STATCOM design studies are based on the assumption of the balanced three-phase system. And almost all researches are based on the three-phase three-wire systems Moreover this paper presents the D-STATCOM using IGBT voltage source inverter with $10 \mathrm{kHz}$ switching frequency PWM operation for reactive power compensation in distribution system. AC voltage directs control has the advantages of improved harmonic performance, and sag voltage.

\section{STATIC SYNCHRONOUS COMPENSATOR}

Static Synchronous Compensator (STATCOM) is a voltage source converter based FACTS controller. It is a shunt controller mainly used to regulate voltage by generating/absorbing reactive power. The schematic diagram of STATCOM is shown in Fig. 1. STATCOM has no long term energy support in the DC Side and cannot exchange real power with the ac system ; however it can exchange reactive power. The reactive power is varied by varying the magnitude of the converter output voltage. A small phase difference exists between the converter output voltage and STATCOM bus voltage so that real power is drawn from the lines to compensate for the losses. STATCOMs are employed at distribution and transmission levels - though for different purposes. 


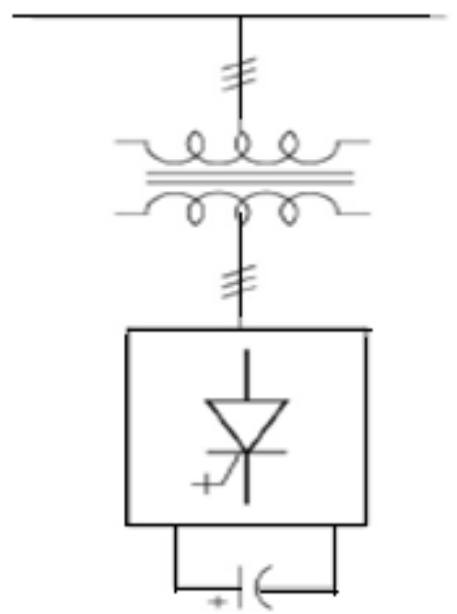

\section{Fig. 1. Schematic diagram of STATCOM}

\section{VOLTAGE SOURCE CONVERTERS (VSC)}

In recent years, voltage source converter technology has made a great progress through the development of high power self-turnoff type semiconductor devices. The rating for converter of this type in practical application has already reached as high. Because of its advantage over the line commutated type in performance characteristics and compactness, various applications of the voltage source converter have been developed and researched.

Three phase Voltage Source Converter (VSC) is heart of most new FACTS and custom power equipments. It may be employed as a series or shunt element or combination of both, as in case of Unified Power Flow Controller (UPFC). Multilevel Voltage Source Converter topology is superior alternative to multipulse arrangement for high power applications like STATCOM.

Voltage source converters (VSC) are commonly used to transfer power between a dc system and an ac system or back to back connection for ac systems with different frequencies, such as variable speed wind turbine systems[2]. A basic VSC structure is shown in Fig. 2 where Rs and Ls represent the resistance and inductance between the converter ac voltage $\left(\mathrm{V}_{\mathrm{C}}\right)$ and the ac system voltage $(\mathrm{Vs})$ and Is is the current injected into the grid. A dc capacitor is connected on the dc side to produce a smooth dc voltage. The switches in the circuit represent controllable semiconductors, such as IGBT or power transistors. 6-pulse D-STATCOM configuration with the IGBT's used as power devices. The IGBTs are connected anti parallel with diodes for commutation purposes and charging of the DC capacitor. For converter the most important part is the sequences of operation of the IGBTs. The IGBTs signals are referred to the Pulse Width Modulation (PWM) that will generate the pulses for the firing of the IGBTs. IGBTs are used in this simulation because it is easy to control the switch on and off of their gates and suitable for the D-STATCOM.

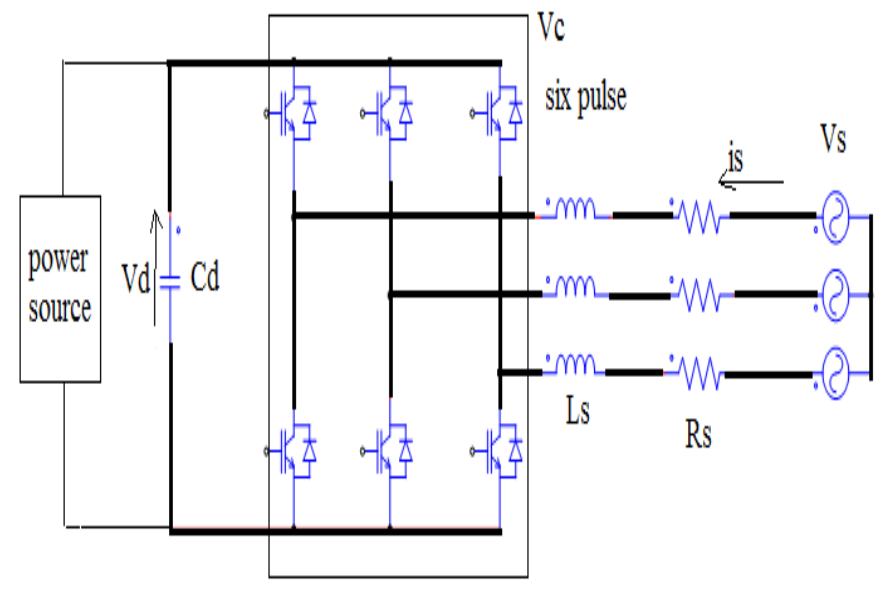

Fig. 2. Voltage source converter (VSC) 


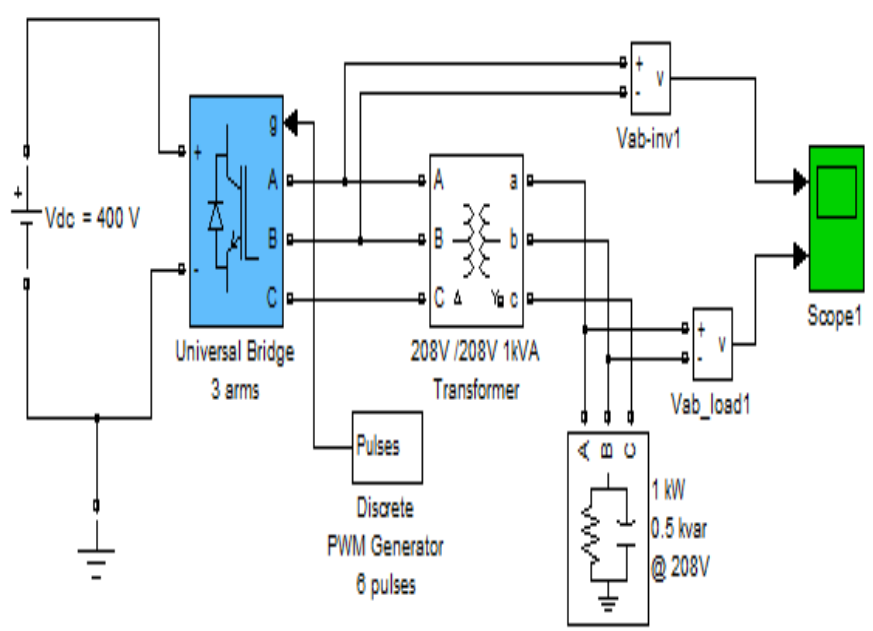

Fig.3.Simulink Model of Voltage Source Converter

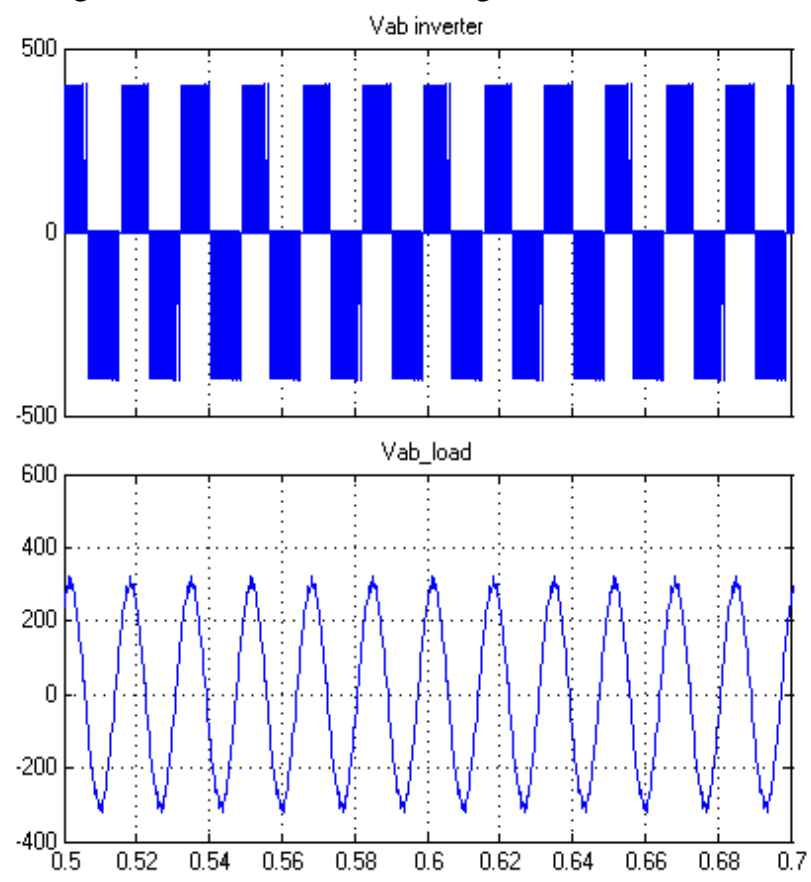

Fig.4. Waveform of Inverter and Load voltage

\section{BASIC CONFIGURATION AND OPERATION OF DSTATCOM}

When a STATCOM is employed at the distribution level or at the load end for power factor improvement and voltage regulation alone it is called D-STATCOM.

Fig. 5 shows a basic configuration diagram of the D-STATCOM. The D-STATCOM mainly consists of DC voltage source behind self-commutated inverters using IGBT and coupling transformer. The IGBT inverter with a DC voltage source can be modeled as a variable voltage source. The distribution power system can also be modeled as a voltage source. 
Two voltage sources are connected by a reactor representing the leakage reactance of the transformer. The principle operation modes of the D-STATCOM output current, I which varies depending upon $\mathrm{V}_{\mathrm{o}}$

$$
I=\left(V-V_{o}\right) / X
$$

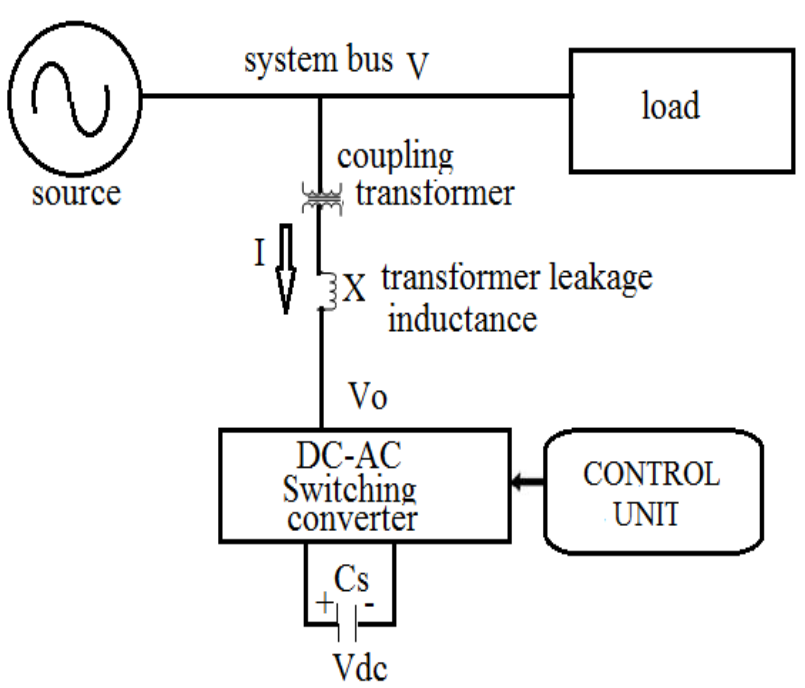

Fig.5.Single-line diagram of D-STATCOM

Where $\mathrm{V}, \mathrm{V}_{\mathrm{o}}, \mathrm{X}$ are the system voltage, output voltage of the IGBT-based inverter, the total ckt reactance respectively.

If $V_{o}$ is equal to $\mathrm{V}$, then no reactive power is delivered to the system.

If $V_{o}$ is greater than $\mathrm{V}$, the phase angle of I is leading with respect to the phase angle of $\mathrm{V}$ by 90 degrees. Thus, a leading reactive power flows in the Capacitive Mode of the D-STATCOM. If $V_{O}$ is lower than V, the phase angle of I is lagging with respect to the phase angle of $\mathrm{V}$ by 90 degrees. Thus, a lagging reactive power flows in the Inductive Mode of the D-STATCOM. The quantity of the reactive power flow is proportional to the difference between $\mathrm{V}$ and $V_{O}$.

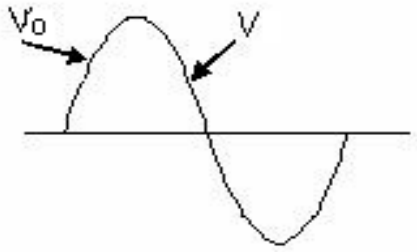

No load mode $(\mathrm{Vo}=\mathrm{V})$

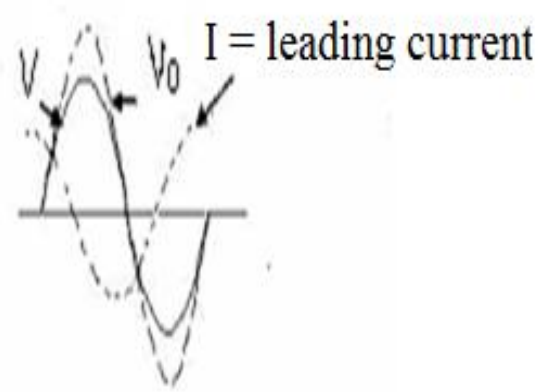

Capacitive Mode (No>V) 
Fig.6. Operation modes of D-STATCOM

\section{MODELING AND CONTROL SCHEME OF D-STATCOM}

A. Principle Of proposed control scheme-:

A simplified block diagram of the internal control for a converter with internal voltage control capability is shown in Fig.7 . The input signals are the bus voltage $\mathrm{V}$, the converter output current io and the reactive current reference, $\mathrm{I}_{\mathrm{Q} R}$ 
The desired terminal voltage versus output current characteristic of the compensator can be established by minor control loop as shown schematically in Fig.8 .

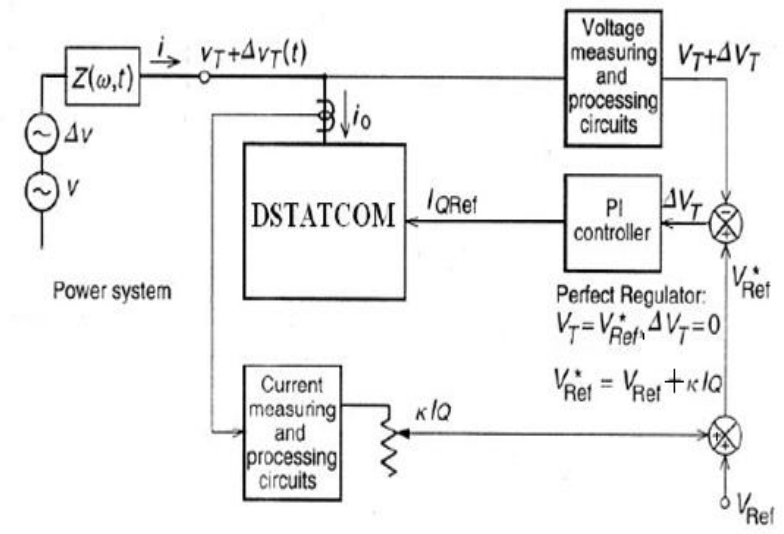

Fig .8. Control model considering implementation of the V-I slope.

A signal proportional to the amplitude of the compensating current $\mathrm{k} I_{Q}$ with an ordered polarity is derived and summed to the reference $V_{R e f}$. The effective reference $V_{R e f}^{*}$ controlling the terminal voltage thus becomes

$$
V_{R e f}^{*}=V_{R e f}+k I_{Q}
$$

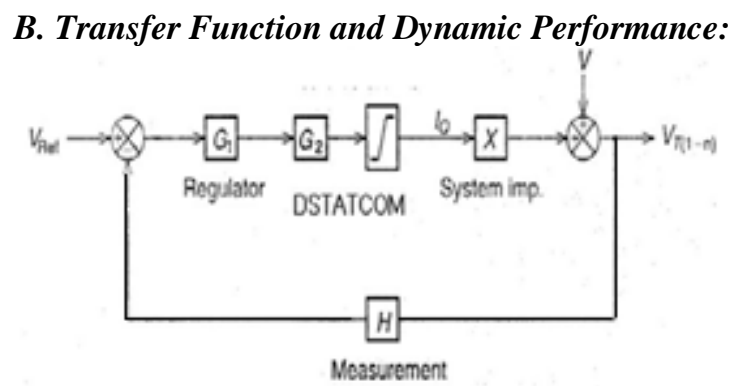

Fig. 9.Basic transfer function block diagram

The basic transfer function block diagram shown in Fig. 9 can characterize the dynamic behavior of the compensator in the normal compensating range. This block diagram is derived directly from the basic control scheme shown in Fig.8.

In the linear operating range of the compensator, the terminal voltage $V_{T}$ can be expressed from Fig. 8 in terms of the internal voltage $\mathrm{V}$ and the reference voltage $\mathrm{V}_{\mathrm{Ref}}$ as follows:

$V_{T}=V \frac{1}{1+G_{1} G_{2} H X}+V_{\operatorname{Re} f} \frac{G_{1} G_{2} X}{1+G_{1} G_{2} H X}$

Since the objective is to establish how well terminal voltage is regulated against the system voltage,

$V_{\text {Ref }}=0$
So $V_{T}=V \frac{1}{1+G_{1} G_{2} H X}$ 
Consider small variation only. Then amplitude variation of terminal voltage and system voltage can be expressed in following form:

$$
\frac{\Delta V_{T}}{\Delta V}=\frac{1}{1+G_{1} G_{2} H X}
$$

Where

$$
\begin{gathered}
G_{1}=\frac{1 / k}{1+T_{1} s} \\
G_{2}=e^{-T_{d} s} \\
H=\frac{1}{1+T_{2} s}
\end{gathered}
$$

Table1: Parameter of D-STATCOM

\begin{tabular}{|l|l|}
\hline \multicolumn{1}{|c|}{ Parameter } & \multicolumn{1}{|c|}{ Value } \\
\hline Main time constant of PI controller & $\mathrm{T}_{1}=10(\mathrm{~ms})$ \\
\hline $\begin{array}{l}\text { Amplitude measuring circuit time } \\
\text { constant }\end{array}$ & $\mathrm{T}_{2}=8(\mathrm{~ms})$ \\
\hline Transport lag of D-STATCOM & $\mathrm{T}_{\mathrm{d}}=0.2(\mathrm{~ms})$ \\
\hline Reactive part of system impedence & $\mathrm{X}=9.522$ \\
\hline Regulation slope & $\mathrm{K}=0.03$ \\
\hline
\end{tabular}

$$
\begin{aligned}
& G_{1}=\frac{33.33}{1+10 s} \\
& G_{2}=e^{-0.2 s}=\frac{1}{e^{0.2 s}}=\frac{1}{1+0.2 s} \quad \text { (neglecting higher order term) } \\
& \mathrm{H}=\frac{1}{1+8 s} \\
& G_{1} G_{2} H X=\frac{317.37}{16 s^{3}+83.6 s^{2}+18.2 s+1}
\end{aligned}
$$

From relation (5) and (6) we get

$$
\frac{\Delta V_{T}}{\Delta V}=\frac{16 S^{3}+83.6 S^{2}+18.2 s+1}{16 s^{3}+83.6 S^{2}+18.2 s+318.37}
$$




\section{Bode-plot command when D-STATCOM regulate voltage}

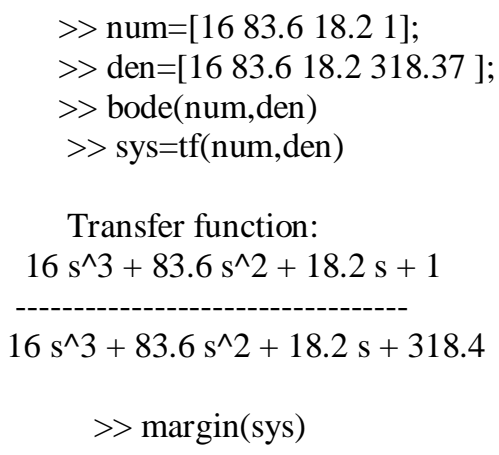

\section{RESULT AND DISCUSSION}

The Bode plot is an important tool for stability analysis of closed-loop systems. Gain and Phase margin can be determined from the bode diagram. Relative stability can be determined from the bode diagram using margin function. The margin function is invoked in conjunction with bode function to compute the gain and phase margin.

Here treating MATLAB as one of the tool to design and analyze control system. From Fig. 10 it is clear that both Phase margin and Gain margin have positive value so the D-STATCOM system is stable.

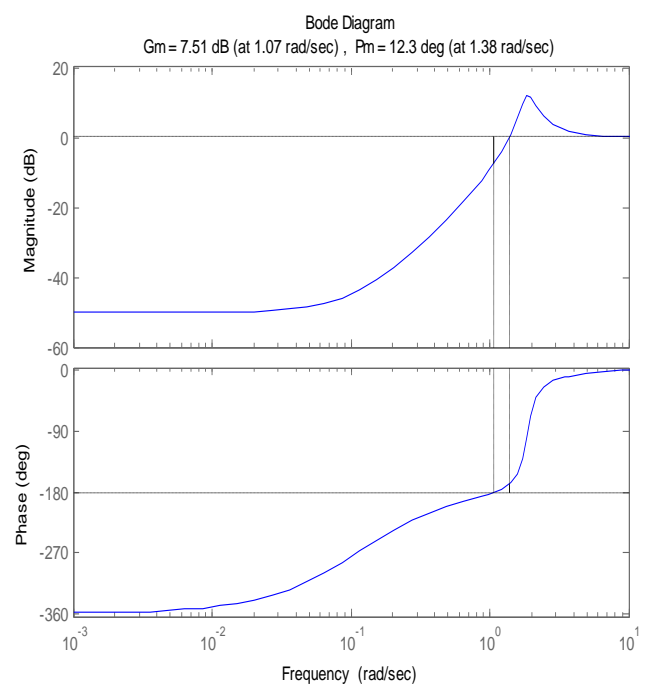

Fig .10. Bode-plot to demonstrate the stability of D-STATCOM

\section{CONCLUSION}

Custom power devices like DVR, D-STATCOM, and UPQC can enhance power quality in the distribution system. Based on the power quality problem at the load or at the distribution system, there is a choice to choose particular custom power device with specific compensation. The working principle of DSTATCOM is explained in two modes (capacitive and inductive) of operation. Modeling and control scheme of D-STATCOM is done with the help of transfer function block diagram and stability analysis is investigated using bode plot with observing gain margin and phase margin of a system transfer function.

\section{Acknowledgments}

The authors are thankful to Government of India. One of the authors Mr. Pradeep Kumar is thankful to All India council of Technical Education (AICTE), Ministry of Human Resources Development (MHRD), Govt. of India for providing financial assistants to do the research work under Technical Quality Improvement Programme (TEQIP). 


\section{References}

[1] John J. Paserba, Gregory F. Reed, Masatoshi Takeda \& Tomohiko Aritsuka ," FACTS and Custom Power Equipment for the Enhancement of Power Transmission System Performance and Power Quality", Symposium of Specialists in Electric Operational and Expansion Planning (VII SEPOPE) Curitiba, Brazil, May 21-26, 2000.

[2] Y. HU Member, IEEE, Zhe CHEN, Senior Member, IEEE, and H. McKenzie "Voltage Source Converters in Distributed Generation Systems “ DRPT2008 6-9 April 2008 Nanjing China.

[3] Hendri Masdi, Norman Mariun S.M. Bashi \&Azah Mohamed, Construction of a Prototype D-Statcom for Voltage Sag Mitigation, European Journal of Scientific Research ISSN 1450-216X Vol.30 No.1 (2009), pp.112-127.

[4] Soo-Young Jung, Tae-Hyun Kim, Seung-Il Moon, Byung-Moon Han, "analysis and control of D-STATCOM for a line voltage regulation". Member, IEEE,pp. 729-734.

[5] N.G.Hingorani “Introducing custom power", IEEE spectrum, vol.32, June 1995, PP.41-48.

[6] N.G.Hingorani and L.Gyugyi, Understanding FACTS: Concepts and Technology of flexible ac transmission systems, IEEE Press, New York, 1999.

[7] K. R. Padiyar Department of Electrical Engineering Indian Institute of Science Bangalore-560 012 ,India. FACTS CONTROLLERS IN POWER TRANSMISSION AND DISTRIBUTION.

[8] Anaya-Lara Olimpo, E.Acha "Modeling and Analysis of custom power systems by PSCAD/EMTDC",IEEE Transactions on Power Delivery, Volume: 17, Issue: 1, Jan 2002 pp: 266-272

[9] Robert H Bishop, The University of texas at austin ,"Modern Control System Analysis and Design using MATLAB” ADDISONWESLEY PUBLISHING COMPANY. 